\title{
Defining successful aging: the need to distinguish pathways from outcomes
}

Motivated by a vision for a "new gerontology" that focuses on optimal functioning rather than losses and declines, Rowe and Kahn (1987) argued that many of the age-related declines that define usual aging are due to modifiable factors such as diet, exercise, personal habits such as smoking, and psychosocial factors. Thus, individuals may engage in lifestyle modifications to avoid diseases and, consequently, enhance their chance of aging well. Three domains of outcomes were said to jointly define successful aging: (a) low probability of disease and disease-related disability, (b) high cognitive and physical functioning, and (c) engagement with life (namely in the form of social connectedness and productive activities; Rowe and Kahn, 1997). All three criteria are meant to be relative (i.e. without absolute thresholds), although subsequent studies tend to adopt a threshold approach (see Depp and Jeste, 2006). The three criteria are somewhat hierarchical, in that avoiding diseases (and associated risk factors) makes high physical and cognitive functioning possible, which in turn enables the individual to engage in social and productive activities (Rowe and Kahn, 1997). However, remaining free of disease/disability and maintaining high physical and cognitive functioning are less likely as one ages, whereas participation in social and even productive activities may not be affected until significant physical and cognitive declines have occurred (McLaughlin et al., 2010; Yaffe et al., 2010; Hsu and Jones, 2012).

There were a number of engaging debates about the merits of this model. Perhaps the most common critique concerns the "biomedicalization" of aging, the image of "physiologic agelessness" seemingly portrayed, the branding of the majority who cannot achieve this standard as "losers," and the bias toward those who are genetically advantaged (Strawbridge et al., 2002; Moody and Sasser, 2012).

Some scholars have argued to let older persons define for themselves whether they are aging well. Not surprisingly, self-rated successful aging, typically on the basis of a single item like "I am aging well," results in much higher proportions of people in the "successful" category, with one study reporting as much as $92 \%$ being successful (Montross et al., 2006). While people may be reluctant to label themselves as being "unsuccessful" and may adopt different frames of mind in the exercise, the measure would be of little practical or theoretical value if almost everyone rates himself or herself the same way. Pruchno et al. (2010), however, argued that both objective (or researcher-defined) and subjective criteria should be incorporated into measuring successful aging, and their structural equation model showed a high correlation between objective and subjective successful aging at the latent variable level $(r=0.65)$. Another approach is to ask lay people to define the contours of successful aging. Aside from attributes that are generally favored regardless of age, such as good health, financial status, enjoyment, and social activities (Bowling, 2006), themes about adaptation to challenges, positive attitudes, acceptance, contentment, and realistic self-appraisal (von Faber et al., 2001; Phelan et al., 2004; Reichstadt et al., 2007) are informative, as discussed below. Another notable finding is that ordinary people do not regard absence of diseases and disability to be an essential component of successful aging as many with health problems selfidentify as successful agers (Strawbridge et al., 2002; Montross et al., 2006; Romo et al., in press).

Furthermore, in contrast to Rowe and Kahn's "outcome-oriented" approach, a number of "process-oriented" models have been proposed (Baltes and Baltes, 1990; Schulz and Heckhausen, 1996; Brandtstädter and Rothermund, 2002). The emphasis is on the management of declines and losses while sustaining the motivation for selfmaintenance or improvement as well as stabilizing subjective self-appraisal. Most notably, the model of selective optimization and compensation (SOC) argues that with age-related declines and losses, individuals need to disengage from unattainable goals. In order to optimize performance, they need to concentrate resources selectively on attainable goals and employ compensatory strategies when necessary. Kahn (2003) considered Baltes and Baltes' model to be complementary to the one by Rowe and Kahn.

I contend that much of the controversy in this field can be resolved by taking the idea of relativity 
more seriously, by distinguishing between pathways and end states, and by expanding the contours of successful aging to include psychological functioning. In the following, I will discuss these issues and a revised conceptual model in which agegraded physical, cognitive, psychological, and social functioning together characterize successful aging.

\section{Disentangling means and outcomes}

Outcomes refer to criteria of success. Means are mechanisms and pathways by which the achievement of outcomes is enhanced. Distinguishing means from outcomes can have far-reaching implications for the concept of successful aging.

As Rowe and Kahn (1998) had commented, "The MacArthur Study ... was rooted in our concept of 'successful aging' - that is, the many factors which permit individuals to continue to function effectively [italics added], both physically and mentally, in old age" (p. xii). It is the present author's view that the subsequent focus of the field on the avoidance of diseases and diseaserelated risk factors as a goal, and its seeming impossibility, is misplaced. Avoiding risk factors and diseases is a pathway to effective functioning, but certainly not the only pathway. I have no intention to downplay the role disease conditions have on various domains of functioning and the importance, from a public health perspective, to avoid diseases and their risk factors. For instance, prevention of obesity alone can lead to significant reductions in cardiovascular diseases, diabetes, cancer, and thus healthcare costs. However, one would not say that an older person is unsuccessful simply because he or she has abdominal obesity. Likewise, Strawbridge and colleagues (2002) commented that "most gerontologists are not ready to call someone unsuccessful merely because he or she is ... diagnosed with diabetes" (p. 728). True, but this debate lingers on only because absence of diseases is treated as an outcome; when it is recognized as a means to achieve effective functioning, its role in successful aging is duly recognized without arousing debates as to whether it is realistic and whether successful aging is a biomedical paradigm. To classify individuals as successful or unsuccessful on the basis of risk factors and diseases may have confused means with meaningful outcomes.

It should be noted that not all diseases have direct bearing on disability or physical functioning. Some common chronic diseases, such as hypertension, hyperlipidemia, and atherosclerosis, are for the most part asymptomatic unless they become very serious. With advances in medicine and assistive technologies, many chronic conditions may have little impact on day-to-day functioning, especially when they are properly managed. Other conditions, especially mental illnesses and dementia, are defined partly on the basis of functional loss (in nonphysical domains) and so their diagnoses already imply compromises in functioning. Thus, not all diseases impair functioning, which may be why many lay people with chronic illnesses consider themselves successful, nonetheless (Strawbridge et al., 2002; Montross et al., 2006; Romo et al., in press). In this connection, it is noteworthy that the availability of neuroimaging techniques to detect Alzheimer-related pathological changes in the brain long before symptom onset, leading to proposals, though controversial (Chiu and Brodaty, 2013), to diagnose such individuals without symptoms as having the disease (Dubois et al., 2010; 2013), presents further problems with the disease-free criterion.

Also concerned with pathways to successful aging are the process models. Let us take a look again at a well-known example cited by Baltes (1993) in support of his model, "When Rubinstein was asked, in a television interview, how he managed to remain such a successful pianist in his old age [italics added], he mentioned three strategies: (1) in old age he performed fewer pieces [selection], (2) he now practiced each piece more frequently [optimization], (3) he introduced more ritardandos in his playing before fast segments so that the playing speed sounded faster than it was in reality [compensation]" (p. 590). Would Baltes have offered this example had Rubinstein's performance been unsuccessful? If a process model has to be validated by outcome, then the value of the model in describing the state of successful aging would be limited in the sense that it cannot do so independent of outcome. This in no way undermines the value of SOC and other theoretical perspectives in articulating the mechanisms and pathways by which the chance of achieving successful aging may be enhanced. These mechanisms are as important as the lifestyle factors emphasized by Rowe and Kahn; they all represent behaviors and strategies that are modifiable even in later life. In the realm of cognitive aging, active and sustained participation in physical and intellectually stimulating activities in order to build up cognitive reserve (Fratiglioni and Wang, 2007; Stern, 2012) cannot be ignored.

Having disentangled means from outcomes, a fundamental issue remains: What constitutes success or effective functioning? Any criteria of success are value judgments, which would likely vary by culture and settings. Rowe and Kahn (1997) argued that the criteria should be relative, with the MacArthur studies mapping participants in the top, middle, and bottom tertile in the population 
across a number of indicators as successful, usual, and pathological agers, respectively (Berkman et al., 1993). Likewise, researchers have classified individuals regardless of age, leading to age being an important determinant of successful aging (Depp and Jeste, 2006). However, why should someone at the age of 65 be regarded as successful simply because he or she is superior to an 85-yearold? Lay people certainly would not compare themselves against younger ones when making self-assessment of successful aging. The lack of reference to age-graded criteria by Rowe and Kahn might have been an unintended consequence of their formulation (Kahn, 2003), stemming from their attempt to separate aging from pathology and success. However, in terms of their vision to engage the population to make the necessary behavioral changes in order to function effectively, this is counter-productive. When the bar is set too high, it is in fact adaptive to disengage; yet such individuals would be labeled as unsuccessful. Guidelines and expectations must be age-appropriate before older adults would identify with them and use them to guide development. The differences between process and outcome models would also be partly reconciled as the former is predicated on the assumption that goals selected must be realistic.

At the same time, it is noteworthy that the meaning of success to individuals goes beyond performance against some reference points, but is also based on individuals' assessments of how they have lived their lives, such as the choices made, under different circumstances. This may be why themes related to adaptation and life satisfaction (including absence of regrets) surface so frequently when older adults are invited to talk about what they think of successful aging (von Faber et al., 2001; Phelan et al., 2004; Reichstadt et al., 2007). In other words, researchers take an interindividual approach whereas lay people may adopt an intraindividual (and life review) approach. Therefore, to challenge researcher-defined criteria using lay people's subjective criteria may not be entirely appropriate due to the different frames of reference involved. Nevertheless, it does not mean that the views of lay people are irrelevant because their identification with expert-defined goals may be crucial for participation in behavioral change programs.

\section{A revised model and concluding comments}

The revised model is one in which high physical, cognitive, psychological, and social functioning jointly define successful aging, measured with reference to age-graded norms. All four dimensions are considered equally as building blocks of successful aging (i.e. without any hierarchical organization as in Rowe and Kahn). A substantial body of literature has demonstrated that these four factors interrelate in complex ways (Depp et al., 2010) and there is no strong reason to treat any dimension as more crucial than another. Disability and physical functioning are closely related and researchers often discuss them together (Depp and Jeste, 2006); hence, they are grouped into one dimension. Because of the focus on functioning rather than disease, a separate definition of successful aging for people with chronic diseases (Young et al., 2009) may not be necessary. Moreover, social and productive engagements are renamed as "social functioning" for convenience. This multidimensional approach to defining high functioning is consistent with World Health Organization's (2002) concept of holistic health.

Additional comments on the dimension of psychological functioning are warranted as it was not included in Rowe and Kahn's model. Although there were psychologists and psychiatrists serving as core members on the MacArthur studies team, the main purpose appeared to be locating psychosocial factors predicting physical and cognitive functioning, rather than looking at psychological functioning per se as an outcome (Rowe and Kahn, 1998). This has led to a relative neglect of psychological well-being in studies on successful aging (Depp and Jeste, 2006). Note, however, that Havighurst (1961) had long ago remarked on the importance of life satisfaction for successful aging, which, together with emotional well-being, are endorsed by the majority of older people as markers of aging well (von Faber et al., 2001; Phelan et al., 2004). Recently, Jeste et al. (2010) emphasized lack of depression as an indicator of successful emotional aging. A distinction has to be made between clinical depression, the mental illness, and depressive mood as an indicator of psychological functioning in the context of the present model. This distinction is not easily made. As mentioned before, as a mental illness, depression necessarily implies compromises in functioning. Using depression as a criterion also tends to bias against women as they report more depressive symptoms than men (Smith and Baltes, 1998). For instance, a recent study in Taiwan (Hsu and Jones, 2012) included depression, along with chronic diseases, physical function difficulties, productive activities, and so on, as criterion and found that $72 \%$ of those with successful aging trajectories were men. Aside from the possibility of differential attrition due to mortality over a 14-year interval, leaving healthier men being retained in the sample, preexisting gender difference 
in depression might have further separated women from men in the identification of latent classes (i.e. groups). In contrast to depression, other indicators of psychological functioning, such as life satisfaction and positive/negative affect, show little or no gender differences (Pinquart and Sörensen, 2001; Cheng et al., 2011). Researchers need to be careful in the selection of measures to avoid biased estimation of gender difference in successful aging.

As mentioned before, the four dimensions do not have similar trajectories with age. Age-related declines in physical and cognitive functioning are evident but social and psychological functioning may change little until very old age. There are virtually universal indicators for each of these dimensions (though cultural adaptation of different measures may be needed). For some of the indicators, such as activities of daily living, Mini-Mental State Examination, and life satisfaction, population data are often available for the construction of age-graded norms. In keeping with Rowe and Kahn's (1997) relativistic approach, successful aging represents those functioning at relatively high levels, which may be empirically established through research. By including measures of psychological well-being like life satisfaction, adopting age-graded expectations, and removing diseases and risk factors from the criteria, the gap between expert and lay definitions of successful aging may be significantly reduced and existing differences between theoretical perspectives may be somewhat reconciled. While this paper has focused on the conceptual issues, let us not forget that the promotion of actual behavioral and lifestyle changes (Lam and Cheng, 2013) representing the means to successful aging is a more pressing issue in the face of global aging.

\section{Conflict of interest}

None.

\section{SHEUNG-TAK CHENG}

Department of Psychological Studies and Center for Psychosocial Health and Aging, Hong Kong Institute of Education, Hong Kong

Email: takcheng@ied.edu.hk

\section{References}

Baltes, P. B. (1993). The aging mind: potential and limits. The Gerontologist, 33, 580-594. doi:10.1093/geront/33.5.580.

Baltes, P. B. and Baltes, M. M. (1990). Psychological perspectives on successful aging: the model of selective optimization with compensation. In P. B. Baltes and
M. M. Baltes (eds.), Successful Aging: Perspectives from the Behavioral Sciences (pp. 1-34). New York: Cambridge University Press.

Berkman, L. F. et al. (1993). High, usual and impaired functioning in community-dwelling older men and women: findings from the MacArthur Foundation Research Network on Successful Aging. Fournal of Clinical Epidemiology, 46, 1129-1140.

Bowling, A. (2006). Lay perceptions of successful ageing: findings from a national survey of middle aged and older adults in Britain. European fournal of Ageing, 3, 123-136. doi:10.1007/s10433-006-0032-2.

Brandtstädter, J. and Rothermund, K. (2002). The life-course dynamics of goal pursuit and goal adjustment: a two-process framework. Developmental Review, 22, 117-150. doi:10.1006/drev.2001.0539.

Cheng, S.-T., Li, K.-K., Leung, E. M. F. and Chan, A. C. M. (2011). Social exchanges and subjective well-being: do sources of positive and negative exchanges matter? The fournals of Gerontology, Series B: Psychological Sciences and Social Sciences, 66B, 708-718. doi:10.1093/geronb/gbr061.

Chiu, H. F. K. and Brodaty, H. (2013). Arguments against the biomarker-driven diagnosis of AD. International Psychogeriatrics, 25, 177-181. doi:10.1017/S1041610212002104.

Depp, C. A. and Jeste, D. V. (2006). Definitions and predictors of successful aging: a comprehensive review of larger quantitative studies. The American fournal of Geriatric Psychiatry, 14, 6-20. doi:10.1097/01.JGP.0000192501.03069.bc.

Depp, C., Vahia, I. V. and Jeste, D. (2010). Successful aging: focus on cognitive and emotional health. Annual Review of Clinical Psychology, 6, 527-550. doi:10.1146/annurev.clinpsy.121208.131449.

Dubois, B., Gauthier, S. and Cummings, J. (2013). The utility of the new research diagnostic criteria for Alzheimer's disease. International Psychogeriatrics, 25, 175-177. doi:10.1017/S1041610212002098.

Dubois, B. et al. (2010). Revising the definition of Alzheimer's disease: a new lexicon. The Lancet Neurology, 9, 1118-1127. doi:10.1016/S1474-4422(10)70223-4.

Fratiglioni, L. and Wang, H. (2007). Brain reserve hypothesis in dementia. Fournal of Alzheimer's Disease, 12, 11-22.

Havighurst, R. J. (1961). Successful aging. The Gerontologist, 1, 8-13. doi:10.1093/geront/1.1.8.

Hsu, H. C. and Jones, B. L. (2012). Multiple trajectories of successful aging of older and younger cohorts. The Gerontologist, 52, 843-856. doi:10.1093/geront/gns005.

Jeste, D. V., Depp, C. A. and Vahia, I. V. (2010). Successful cognitive and emotional aging. World Psychiatry, 9, 78-84.

Kahn, R. L. (2003). Successful aging: intended and unintended consequences of a concept. In L. W. Poon, S. H. Gueldner and B. M. Sprouse (eds.), Successful Aging and Adaptation with Chronic Diseases (pp. 55-69). New York: Springer.

Lam, L. C. W. and Cheng, S.-T. (2013). Maintaining long-term adherence to lifestyle interventions for cognitive health in late life. International Psychogeriatrics, 25, 171-173. doi:10.1017/S1041610212001603. 
McLaughlin, S. J., Connell, C. M., Heeringa, S. G., Li, L. W. and Roberts, J. S. (2010). Successful aging in the United States: prevalence estimates from a national sample of older adults. Fournal of Gerontology: Social Sciences, 65B, 216-226. doi:10.1093/geronb/gbp101.

Montross, L. P. et al. (2006). Correlates of self-rated successful aging among community-dwelling older adults. The American Fournal of Geriatric Psychiatry, 14, 43-51. doi:10.1097/01.JGP.0000192489.43179.31.

Moody, H. R. and Sasser, J. R. (2012). Aging: Concepts and Controversies. Thousand Oaks, CA: Pine Forge Press.

Phelan, E. A., Anderson, L. A., LaCroix, A. Z. and Larson, E. B. (2004). Older adults' views of "successful aging" - how do they compare with researchers' definitions? Foumal of the American Geriatrics Society, 52, 211-216. doi:10.1111/j.1532-5415.2004. 52056.x.

Pinquart, M. and Sörensen, S. (2001). Gender differences in self-concept and psychological well-being in old age: a meta-analysis. Fournal of Gerontology: Psychological Sciences, 56B, P195-P213. doi:10.1093/geronb/56.4.P195.

Pruchno, R. A., Wilson-Genderson, M. and Cartwright, F. (2010). A two-factor model of successful aging. Fournal of Gerontology: Psychological Sciences, 65B, 671-679. doi:10.1093/geronb/gbq051.

Reichstadt, J., Depp, C. A., Palinkas, L. A., Folsom, D. P. and Jeste, D. V. (2007). Building blocks of successful aging: a focus group study of older adults' perceived contributors to successful aging. The American Fournal of Geriatric Psychiatry, 15, 194-201. doi:10.1097/JGP.0b013e318030255f.

Romo, R. D. et al. (in press). Perceptions of successful aging among diverse elders with late-life disability. The Gerontologist. doi:10.1093/geront/gns160.
Rowe, J. W. and Kahn, R. L. (1987). Human aging: usual and successful. Science, 237, 143-149. doi:10.1126/science.3299702.

Rowe, J. W. and Kahn, R. L. (1997). Successful aging. The Gerontologist, 37, 433-440.

Rowe, J. W. and Kahn, R. L. (1998). Successful Aging. New York: Random House.

Schulz, R. and Heckhausen, J. (1996). A life span model of successful aging. American Psychologist, 51, 702-714. doi:10.1037/0003-066X.51.7.702.

Smith, J. and Baltes, M. M. (1998). The role of gender in very old age: profiles of functioning and everyday life patterns. Psychology and Aging, 13, 676-695. doi:10.1037/0882-7974.13.4.676.

Stern, Y. (2012). Cognitive reserve in ageing and Alzheimer's disease. The Lancet Neurology, 11, 1006-1012. doi:10.1016/S1474-4422(12)70191-6.

Strawbridge, W. J., Wallhagen, M. I. and Cohen, R. D. (2002). Successful aging and well-being: self-rated compared with Rowe and Kahn. The Gerontologist, 42, 727-733. doi:10.1093/geront/42.6.727.

von Faber, M. et al. (2001). Successful aging in the oldest old: who can be characterized as successfully aged? Archives of Internal Medicine, 161, 2694-2700.

World Health Organization (2002). Active Ageing: A Policy Framework. Geneva: World Health Organization.

Yaffe, K. et al. (2010). The effect of maintaining cognition on risk of disability and death. Fournal of the American Geriatrics Society, 58, 889-894.

Young, Y., Frick, K. D. and Phelan, E. A. (2009). Can successful aging and chronic illness coexist in the same individual? A multidimensional concept of successful aging. Fournal of the American Medical Directors Association, 10, 87-92. 